\title{
DELIRIUM IN ELDERLY INDIVIDUALS WITH HIP FRACTURE: CAUSES, INCIDENCE, PREVALENCE, AND RISK FACTORS
}

\author{
Maria Elizabet Furlaneto and Luiz Eugênio Garcez-Leme
}

Furlaneto ME, Garcez-Leme LE. Delirium in elderly individuals with hip fracture: causes, incidence, prevalence, and risk factors. Clinics. 2006;61(1):35-40.

OBJECTIVES: To determine the incidence, prevalence, risk factors, and causes of delirium in elderly individuals with hip fractures, as well as the impact of delrium on mortality and length of hospital stay.

PATIENTS: One hundred and three patients aged 65 and older with hip fractures were included consecutively between January 2001 and June 2002.

METHOD: Delirium was diagnosed using the Confusion Assessment Method, applied within the first 24 hours after admission, and then daily. All patients underwent a global geriatric evaluation including clinical history, physical examination, laboratory tests, surgical risk evaluation, and functional and mental evaluations. Patients with delirium (cases) were compared with patients without delirium (controls).

RESULTS: Thirty (29.1\%) patients in this sample met the criteria for delirium, with a prevalence of 16.5\% (17/103) and an incidence of $12.6 \%$ (13/103). Cognitive and functional deficits had a significant association with delirium, although only cognitive deficit was revealed to be an independent risk factor after analysis with the logistic regression model. The most frequent causes of delirium were drugs and infections. The hospital stay was significantly longer for patients with delirium compared with patients in the control group (26.27 versus 14.38 days, respectively). Mortality showed a tendency to higher levels in patients with delirium during their hospital stay, although with no statistical significance.

CONCLUSIONS: Delirium is a frequent complication among hospitalized elderly individuals with hip fractures. It is associated with cognitive and functional deficits, and it is associated with increases the length of hospital stay and mortality.

KEYWORDS: Delirium. Elderly Individuals. Hip fractures. Confusion Assessment Method.

\section{INTRODUCTION}

Delirium is considered the most frequent complication among hospitalized elderly, ${ }^{1}$ particularly among those undergoing orthopedic surgical interventions. ${ }^{2-4}$

Often, delirium is not recognized by health professionals, either due to the clinical condition itself (which may be misinterpreted as depression, dementia, or even the

Geriatric Orthopedic Group, Institute of Orthopedics and Traumatology, Hospital das Clínicas, São Paulo University Medical School - São Paulo/SP Brazil.

Email: lueglem@usp.br

Received for publication on August 31, 2005.

Accepted for publication on November 22, 2005. physiological aging process ${ }^{5}$ ) or due to the variability of symptoms, as well as to the concomitance of etiologic factors, which may induce confusion and complicate diagnosis. ${ }^{6-8}$

Delirium has been associated with poor prognosis for functional recovery and increases in length of hospital stay, rates of mortality, and discharges to nursing facilities. Cognitive and functional impairment may be observed up to 2 years after the onset of the condition. ${ }^{9-13}$

The Institute of Orthopedics and Traumatology of Hospital das Clínicas, the São Paulo University Medical School, has a geriatric orthopedic ward, assisted by a team of geriatricians and gerontologists in addition to orthopedists. We only found a single Brazilian clinical trial concerning de- 
lirium that tested the validity and reliability of a the Confusion Assessment Method (CAM) diagnostic tool, which is widely employed in international research. ${ }^{14,15}$

Falls are relatively common occurrences among the elderly and a recent study shows that elders with a moderate level of fitness fall more frequently those with a higher degree, even though the latter seem to sustain more serious injuries than the latter. ${ }^{16}$ In the present study, we analyzed delirium in patients aged 65 and older admitted to that ward with proximal hip fractures. Our objective was to administer a survey addressing incidence and prevalence, risk factors, and causes of delirium, aiming at obtaining data from our own environment that would allow us to establish criteria for recognition, prevention, and management of this syndrome, as well as to establish strategies for functional recovery.

\section{PATIENTS AND METHODS}

\section{Patients}

One hundred and three patients of either sex, aged 65 and older, admitted to the geriatric orthopedic ward, were consecutively evaluated between January 2001 and June 2002 .

\section{Methods}

The study was approved by the Institutional Ethics Committee, and patients (or their guardians) gave written informed consent to participate in the trial. All patients included in this study underwent a global clinical and geriatric evaluation including clinical history, physical examination, laboratory tests, surgical risk evaluation using the ASA Index, ${ }^{17}$ and Goldman's Multifactorial Index of Cardiac Risk. ${ }^{18}$

Ninety-nine patients underwent surgery, and 4 did not. Data concerning 2 surgeries were not retrieved.

We assessed mental state using Folstein's Mini-Mental State Examination (MMSE) ${ }^{19}$ and the 10-Item Clock Drawing Test. ${ }^{20}$ By questioning patients and/or caregivers using the Katz's Daily Life Activities (ADL) Index, ${ }^{21}$ we were able to rebuild a functional evaluation for immediately prior to hip fracture.

The previous cognitive state was estimated from administering the Blessed dementia scale questionnaire ${ }^{22}$ to the patient's caregiver or to a person who had frequent contact with the patient. A score above 4 was considered indicative of previous dementia. Eighty-four caregivers underwent the Blessed interview. We did not use MMSE and Clock Drawing Test as indicators of dementia or delirium, because hip fracture is a highly stressful circumstance; consequently, any test applied directly to patient would be open to objection on account of lack of reliability.

Delirium was diagnosed from the daily administration of the $\mathrm{CAM}^{14,15}$ and from actively questioning the nurses.

At all times, the scales employed were validated for their Portuguese language version.

The first evaluation was always made within the first 24 hours after admission, followed by daily evaluations.

The following laboratory tests were performed: complete blood count with platelets, coagulogram, arterial gasometry, free T4, TSH, TGO, TGP, urea, creatinine, sodium, potassium, calcium, phosphorus, albumin, as well as quantification of urine sediment and creatinine clearance calculated by the Cockroft-Gault formula ${ }^{23}$; other tests were performed according to the needs of each patient. Urine culture was performed in all patients; those who had positive urine culture were treated before the surgery.

The causes of delirium were categorized into 8 classes: 1) drugs; 2) infections; 3 ) hydroelectrolytic balance disorder; 4) metabolic/endocrinologic disorder; 5) intracranial process; 6) cardiopulmonary impairment and/or hypoxia; 7) alcohol or drug withdrawal; and 8) delirium caused by sensorial impairment and/or environmental factors.

We analyzed the following variables as possible risk factors: age, sex, education level, visual and auditory deficiencies, functional state, mental state, preexisting diseases (by number and by disease), drugs (by number and by class), surgical risk (ASA and Goldman), creatinine clearance, $\mathrm{Hb}$, albumin, and type and duration of anesthesia.

\section{Statistical Analysis}

For the analysis of categorical data, the chi-square test and Fisher's Exact Test were used; For the analysis of continuous data, the Mann-Whitney and Student $t$ test were used.

Variables considered to be possible risk factors for delirium were compared one by one with the dependent variable (delirium). Those that had a significant association with the event $(P<.05)$ were entered into logistic regression models to establish independent risk factors associated with delirium.

The data analysis was performed using SPSS software (Statistical Package for Social Sciences, SPSS Inc).

\section{RESULTS}

One hundred and three patients were followed during their hospital stay. Thirty $(29.1 \%)$ patients in the sample met delirium criteria. Of these, 17 were delirious at admission, and 13 presented the disorder in the postoperative pe- 
riod. Therefore, we had prevalence of $16.5 \%$ and incidence of $12.5 \%$. We adopted this criterion for prevalence and incidence because although it is probable that the hip fracture had lead to delirium, it is possible that previous delirium could have lead to the fall that resulted in fracture. Thirty cases of delirium were compared with the remaining 73 patients that constituted the control group. Table 1 shows the main characteristics of study population. Age, sex, and educational level were comparable between cases and controls. Cases had worse baseline functional status than controls. Additionally, patients with delirium had greater baseline cognitive impairment than controls (Blessed Index > 4). During hospitalization, the MMSE and Clock Drawing Test scores were lower among cases as compared to controls.

Table 1 - Characteristics of the population (mean, \pm SD)

\begin{tabular}{llll}
\hline Variables & $\begin{array}{l}\text { Controls } \\
(\mathrm{n}=73)\end{array}$ & $\begin{array}{l}\text { Delirium } \\
(\mathrm{n}=30)\end{array}$ & $(P)$ \\
\hline Demographics & & & \\
Age & $80.1( \pm 8.5)$ & $82.5( \pm 8.0)$ & .19 \\
Sex, F/M (n) & $60 / 13$ & $25 / 5$ & $.89^{\dagger}$ \\
Educational Level & $4.10( \pm 3.48)$ & $5.01( \pm 3.76)$ & .15 \\
Mental assessment & & & \\
MMSE & $17.74( \pm 8.78)$ & $12.07( \pm 9.04)$ & .03 \\
Clock Drawing & $4.73( \pm 3.10)$ & $3.00( \pm 2.34)$ & .01 \\
Blessed & $5.98( \pm 7.29)$ & $9.48( \pm 6.81)$ & $.02^{*}$ \\
Functional Status & & & \\
ADL & $8.22( \pm 3.60)$ & $9.33( \pm 3.45)$ & $.02^{* *}$ \\
Medical Condition & & & \\
Diseases (number) & $2.53( \pm 1.53)$ & $2.70( \pm 1.64)$ & .71 \\
Drugs (number) & $2.30( \pm 2.02)$ & $2.83( \pm 2.18)$ & .25 \\
Hemoglobin & $11.43( \pm 1.80)$ & $11.97( \pm 1.84)$ & .13 \\
Albumin & $3.50( \pm 0.47)$ & $3.46( \pm 0.51)$ & .82 \\
Creatinine Clearance & $47.00( \pm 21.06)$ & $43.44( \pm 16.82)$ & .42 \\
Anesthesics Duration (min) & $191.14( \pm 58.72)$ & $201.93( \pm 44.55)$ & .34 \\
Hospital Stay & $14.38( \pm 8.80)$ & $26.27( \pm 30.10)$ & $.02^{* * *}$ \\
Deaths & 3 & 4 & $.19^{\ddagger}$ \\
\hline
\end{tabular}

$\dagger \mathrm{OR}=0.92,95 \% \mathrm{CI}=0.25-3.23 ;$ †OR $=3.54,95 \% \mathrm{CI}=0.69-20.11$; $\mathrm{RR}=3.24,95 \% \mathrm{CI}=0.77-13.63$

The average hospital stay of the patients with delirium was 26.3 days versus 17.8 days of the sample as a whole and 14.4 days for patients in the control group. A comparison between case and control groups shows a significant association between delirium and hospital stay.

There were 7 (6.8\%) deaths, with 4 of them occurring in the patients who met delirium criteria. There was no significant relationship between the number of deaths and delirium.

The average duration of delirium was of 10.2 days per patient $($ minimum $=1 ;$ maximum $=62 ;$ mean $=4.5 ; \mathrm{SD}=$ 15.4). Five patients $(16.0 \%)$ still met delirium criteria by the time they were discharged. Regarding the etiology of the dilerium, in $3(9.7 \%)$ cases it was not possible to es- tablish the etiology; single causes were identified in 19 cases $(61.3 \%)$, and in $9(29 \%)$ cases we observed more than 1 cause. Twenty-eight etiologies were involved in the development of delirium in these cases, with an average of 3.1 etiologies per case. Regarding the specific etiologies, the most frequent were infections, medications, environmental/sensorial, and hydroelectrolytic disorders. We found 11 infectious diseases implied in the etiology; 5 of them were bronchopneumonic processes, 3 were urinary tract infections, and 3 were surgical wound infections. Antidepressants (5), benzodiazepinics (4), and antiparkinsonian agents (3) were the drugs most related to the triggering of delirium. Although drugs were involved in 12 cases, they were always associated with other causes. Severe medical conditions such as infections and low-perfusion state were single and definitive causes of delirium. Among 47 causes, 19 were single and definitive and 28 were comorbid conditions for the remaining 8 cases of delirium. In 3 cases, it was not possible to identify the etiology.

Cognitive and functional deficits were significantly related to delirium, although functional deficit lost its significance when introduced into a logistic regression model. From the regression model, cognitive deficit was a predictor of delirium with an odds ratio of $3.043(\mathrm{CI}=1.243$ 7.405)

\section{DISCUSSION}

In spite of the increasing number of surgical procedures in the elderly, little of the medical literature is specifically directed towards perioperative care in this group. ${ }^{24} \mathrm{Hip}$ fracture is a very frequent medical condition in this population $^{25}$. Delirium is considered the most frequent complication among elderly inpatients, ${ }^{1}$ particularly among those who undergo orthopedic surgical interventions..$^{2-4}$

We have studied this syndrome in a population of 103 elderly patients who had suffered hip fracture. Our sample included patients with a high level of clinical complexity, since ours is a hospital to which patients with severe primary diseases are referred, and we did not make any restriction concerning their inclusion in the study.

Even though we administered a structured interview, it is possible that many diseases were omitted. The Blessed interview administered to the caregiver allowed us to suspect that 46 patients might be suffering from some kind of dementia; however, only 12 patients (and/or caregivers) spontaneously reported a dementia syndrome. These data may reflect in part the confusion existing between senescence and senility that often causes medical conditions to be faced as part of the normal aging process. ${ }^{5}$

Patients had an average of 2.58 diseases and used 2.46 
drugs. These numbers are higher than those reported by Ramos et al in a survey conducted in the city of São Paulo city. ${ }^{26}$

In our opinion, the higher incidence of affections in our study, as well as the higher number of medications used, is due to the fact that hip fractures in the elderly are often an epiphenomenon that occurs in patients who are already fragile. Evidence of the severity of primary diseases in the patients in this study is the high overall mortality rate, which was $6.8 \%$. We did not perform a classification of severity of diseases in our study, which is a limitation, because mortality in patients with delirium correlates better with disease severity than with its number or type. ${ }^{10}$

Two decades ago, delirium was considered a benign, transient, short-lived occurrence. In recent years, this concept has changed radically based on the observation that patients presenting mental alterations during the hospital stay have a worse prognosis, stay longer in the hospital, and have higher mortality rates; they also exhibit worse functional recovery and higher institutionalization rates after hospital discharge. ${ }^{27,28,29}$ The results of this study tend to confirm previously reported data; in our series of cases, hospital stays were significantly longer for patients with delirium when compared to those who had no such complication.

We found that $5(16 \%)$ of our patients still met CAM's criteria for the diagnosis of delirium at discharge; patients with isolated symptoms were not counted. This information reinforces the idea that we are not dealing with a transient phenomenon, as we thought, but with a long lasting one $^{29}$ which may even be the first manifestation of dementia that had not yet been identified; alternatively, it may predispose patients to dementia. ${ }^{10-12}$ Although the average duration of the confused state in our sample was 10.2 days, we had a very large variance in this statistic; some patients who remained delirious for 50 to 60 days, and were discharged with delirium (16\%), or with isolated symptoms of the syndrome that we did not have the chance to further evaluate.

Mortality tended to higher levels in the group with delirium, with an odds ratio of 3.54; however, it was not statistically significant. Among the 30 patients with delirium, 4 died, while 3 died among the 73 control patients. This shows a tendency that might have become significant if the sample size had been larger. It is worth mentioning that most authors relate mortality rates to the severity of primary diseases rather than to delirium itself, ${ }^{27,28}$ however, as mentioned previously, we did not measure severity of baseline diseases.

A number of clinical and surgical conditions can trigger delirium. ${ }^{3,10}$ The most frequently reported causes in- clude infectious processes, drug toxicity, and hydroelectrolytic and metabolic disorders. In a large number of cases, more than 1 cause is identified. In our study, we found that $29 \%$ of the cases had multiple etiologies (3.1 per patient). The relationship between delirium and the triggering causes became definitive when dealing with more severe diseases such as infections and diseases of cardiopulmonary origin. In general, drugs constituted the most frequently found etiologic factor, being involved in 12 cases, although it must be emphasized that in none of the patients was the drug toxicity was considered a definitive and single causal factor, since drugs were always associated with other causes. This is a limitation in our study, since any drug can trigger delirium; we should have conducted a study on causes with a larger sample size.

Cognitive deficit is identified in the medical literature as the main risk factor for delirium. ${ }^{30}$ In our study, cognitive and functional deficits were related to delirium, although functional deficit lost its significance when introduced into a logistic regression model. Cognitive deficit remained a significant predictor of delirium in the logistic regression model.

With cognitive deficit being the unique independent risk factor for delirium, investigators studying this issue are faced with the real question, ie, "What is the relationship between delirium and dementia; can these syndromes be separated from one another?" Some authors ${ }^{31}$ consider delirium and dementia to be different stages of similar phenomena with both resulting from insufficiencies of cerebral metabolic processes, the first being transient in character and the second, irreversible.

The separation of the two syndromes-delirium and dementia-occurred after the publication of the DSM III (Diagnostic and Statistical Manual of Mental Disorders, $3^{r d}$ edition), when the diagnostic criteria of these two syndromes were individualized. ${ }^{32-34}$ This allowed great advances in the clinical epidemiology of delirium, although it did not bring further the understanding of its pathophysiological mechanisms. ${ }^{35}$

Pathogenetic mechanisms have been proposed for both find anatomical and biochemical alterations in Alzheimer's disease; however, in the case of delirium, these remain unconfirmed hypotheses.

Considering that it is difficult to clinically distinguish delirium from dementia, ${ }^{36}$ that delirium can occur without a triggering cause during Alzheimer's disease and vascular dementia, ${ }^{37}$ and that a significantly higher cognitive decline is observed up to 2 or 3 years after the onset of delirium in patients without previous cognitive deficit, it seems that there is a limited relationship between the two entities, with delirium being either a symptom of a previ- 
ously undetected cognitive deficit or being a factor that predisposes patients towards dementia by means of yet unknown mechanism. ${ }^{11,12,27,28}$

Evidence shows that preventive measures against delirium are not very effective in preventing it in very old people with a primary dementia condition, ${ }^{38-40}$ which, combined with the previously-mentioned considerations, seems to point to the need for studies on delirium directed towards the pathophysiological mechanisms and the investigation of alternative drug treatments.

Additionally, we think that the effort to improve identification of cases is valid, as well as is the establishment of preventive measures, since is known that elderly people without evident cognitive impairment benefit from such measures and that those who develop delirium, even with no previous cognitive deficit, are at a higher risk for dementia. However, the question, "Is delirium a marker for undetected dementia or does it contribute to the development of dementia?" remains unanswered.

In conclusion, delirium is a frequent complication in elderly patients with hip fractures; it is a symptom that alerts clinicians to previous fragility conditions, the need for prompt management of the triggering causes, and the establishment of optimal conditions of functional recovery. We believe that further studies are required to reveal pathogenetic mechanisms and new alternatives for treatment.

\section{RESUMO}

Furlaneto ME, Garcez-Leme LE. Delirium em idosos com fratura de fêmur: causas, incidência, prevalência e fatores de risco. Clinics. 2006;61(1):35-40.

OBJETIVOS: Deteminar a incidência, prevalência, fatores de risco e causas de delirium em idosos com fratura de fêmur, e seu impacto sobre mortalidade e permanência hospitalar.

MÉTODOS: Cento e três pacientes com 65 anos e mais com fratura de fêmur foram avaliados consecutiva e prospectivamente. Delirium foi diagnosticado usando o Confusion Assessment Method, aplicado diariamente. Todos os pacientes tiveram avaliação geriátrica global e acompanhamento diário por geriatra.

RESULTADOS: Trinta (29.1\%) pacientes na amostra tiveram diagnóstico de delirium, com prevalência de $16.5 \%$
(17/103) e incidência de 12.6\% (13/103). Deficits cognitivo e funcional tiveram associação significativa com delirium, mas apenas déficit cognitivo prévio pôde ser considerado fator de risco independente. As causa mais comuns foram drogas e infecções. A permanência hospitalar foi significativamente maior nos pacientes que tiveram delirium (26.27 versus 14.38 days). A mortalidade também foi maior nesses pacientes, embora sem significância estatística.

CONCLUSÕES: Delirium é complicação freqüente em idosos internados por fratura de fêmur. Está associado a déficits cognitivo e funcional. Déficit cognitivo é preditor de delirium. Aumenta mortalidade e tempo de internação.

UNITERMOS: Delirium. Pacientes Idosos. Fratura de Fêmur. Confusion Assessment Method.

\section{REFERENCES}

1. Kaplan NM, Palmer BF, Roche V. Etiology and management of delirium Am J Med Sci. 2003; 325(1): 20-30.

2. Gustafson Y, Berggren D, Brannström B, Bucht G, Norberg A, Hansson I, et al. Acute confusional states in elderly patients treated for femoral neck fracture. J Am Geriatr Soc. 1988;36:525-30.

3. Brauer C, Morrison RD, Silberzweig SB, and Siu AL. The cause of delirium in patients with hip fracture. Arch Intern Med. 2000;160(12):1856-60.

4. Edlund A, Lundström M, Brannström B, Bucht G, Gustafson Y. Delirium before and after operation for femoral neck fracture. J Am Geriat Soc. 2001:49:1335-40
5. Inouye SK. The dilemma of delirium: clinical and research controversies regarding diagnosis and evaluation of delirium in hospitalized elderly medical patients. Am J Med. 1994;97:278-88.

6. Rockwood K, Cosway S, Stolee P, Kydd D, Carver D, Jarret P, O'Brien $\mathrm{B}$. Increasing the recognition of delirium in elderly patients. J Am Geriatr Soc. $1994 ; 42: 252-6$

7. Pompei P, Foremam M, Rudberg MA, Inouye SK, Braund V, Cassel CK. Delirium in hospitalized older persons: outcomes and predictors. J Am Geriatr Soc. 1994;42:809-15.

8. Lewis LM, Miller DK, Morley JE, Nork MJ, Lasater LC. Unrecognized delirium in ED geriatric patients. Am J Emerg Med. 1995;13(2):142-5. 
9. Cole M, Primeau F. Prognosis of delirium in elderly hospital patients. Can Med Assoc J. 1996;149(1):41-6.

10. Francis J, Martin M, Kapoor WN. A prospective study of delirium in hospitalized elderly. JAMA. 1990;263(8):1097-2101.

11. Rockwood K, Cosway S, Carver D, Jarret P, Stadnyk K, Fisk J. The risk of dementia and death after delirium. Age Ageing. 1999;28(6):551-6.

12. Rahkonen T, Luukkainnen-Markkula R, Paanila S, Sivenius J, Sulkava R. Delirium episode as a sign of undetected dementia among community dwelling elderly subjects: a 2 year follow up study. J Neurol Neurosurg Psychiatry. 2000;69:519-21.

13. McCusker J, Dendukuri N, Belzile E, Cole M, Primeau F. Delirium in older medical inpatients and subsequent cognitive and functional status: a prospective study. Can Med Assoc J. 2001;165(5):575-83.

14. Fabri RMA, Moreira MA, Garrido R, Almeida OP. Validity and reliability of the Portuguese version of the Confusion Assessment Method (CAM) for the detection of delirium in the elderly. Arq Neuropsiquiatr. 2001;59(2A):175-9.

15. Inouye SK, Vandick CH, Alessi CA, Balkin S, Siegal AP, Horwitz RI. Clarifying confusion: a new method for detection of delirium. Ann Intern Med. 1990;113(12):941-8.

16. Ishizuka MA, Mutarelli EG, Yamaguchi, AM, Yamaguchi AM, Jacob Filho W. Falls by elders with moderate levels of movement functionality. Clinics. 2005;60:41-46

17 Vacanti CJ, Vanhouten R, Hill RC. A statistical analysis of the relationship of physical status to postoperative mortality in 68,388 cases. Anesth Analg. 1970;49(4):564-6.

18. Goldman L, Caldera DL, Nussbaun R, Southwuick FS, Kogstad D, Murray B, Burke DS, O'Malley T, Goroll AH, Caplan CH, Nolan J, Carabello B, Slater EE. Multifactorial index of cardiac risk in noncardiac surgical procedures. N Engl J Med. 1977;297:845-50.

19. Folstein MF, Folstein SE, Macgugh PR. Mini-Mental state: a practical method of grading the cognitive state of patients for the clinician. J Psychiatry Res. 1975;12:189-98.

20. Sunderland T, Hill JL, Mellow AL. Clock drawing in Alzheimer's disease. A novel measure of dementia severity. J Am Geriatr Soc. 1989;37:725-9.

21. Katz S, Ford AB, Moskowitz RW. Studies of illness in the aged. The index of ADL: a standardized measure of biological and psychosocial function. JAMA. 1963; 185(12):914-9.

22. Blessed G, Tomlinson BE, Roth M. The association between quantitative measures of dementia and senile change in cerebral grey matter of elderly subjects. Brit J Psychiatry. 1968;114:797.

23. Cockroft DW, Gault MH. Prediction of creatinine clearance from serum creatinine. Nephron. 1976;16(1):21-41.

24. Beliveau MM, Multach M. Perioperative care for the elderly patient. Med Clin North Am. 2003;87(1):273-89.
25. DATASUS/MS, BRAZILIAN MINISTRY OF HEALTH, 2000, [s.l.] Available www.saude.sp.gov.br/ftpsessp/dsaude/informes/5morb_5059/Tabela12.xls; www.saude.sp.gov.br/ftpsessp/dsaude/informes/ 5morb_50-59/Tabela14.xls; www.saude.sp.gov.br/ftpsessp/dsaude/ informes/5morb_50-59/Tabela15.xls. Accessed in December 3, 2003.

26. Ramos LR, Etsuko T, Oliveira ZM. Profile of the elderly in a metropolitan area of Southeastern Brazil: results of a household survey. Rev Saude Publica. 1993;27(2):87-94.

27. Francis J, Kapoor WN. Prognosis after hospital discharge of older medical patients with delirium. J Am Geriatr Soc. 1992;40:601-6.

28. O'Keeffe S and LAVAN J. The prognostic significance of delirium in older patients. J Am Geriatr Soc. 1997;45:174-8.

29. Marcantonio E, Simon S, Bergmann M, Jones R, Murphy K, Morris J. Delirium symptoms in post-acute care: prevalent, persistent, and associated with poor functional recovery. J Am Geriat Soc. 2003;51(1):4-9.

30. Elie M, Cole MG, Primeau F, Bellavance F. Delirium risk factors in elderly hospitalized patients. J Gen Intern Med. 1998;13:204-12.

31. Engel GL, Romano J. Delirium, a syndrome of cerebral insufficiency. J Chronic Dis 1959; 9:260-77; apud Blass PB, Gibson GE: Cerebrometabolic aspects of delirium in relationship to dementia. Dement Geriatr Cogn Disord. 1959;10:335-8.

32. American Psychiatry Association. Diagnostic and Statistical Manual of Mental Disorders. $3^{\mathrm{a}}$ ed. Washington, D.C., 1980.

33. Blass JP, Gibson GE. Cerebrometabolic aspects of delirium in relationship to dementia. Dement Geriatr Cogn Disord. 1999;10:335-8.

34. MacDonald AJD, Treloar A. Delirium and dementia: are they distinct? J Am Geriatr Soc. 1996;44:1001-2.

35. Francis J. A half-century of delirium research: time to close the gap. J Am Geriatr Soc. 1995;43:585-6.

36. Lipowiski ZJ. Delirium in the elderly patient. N Eng J Med. 1989;320:578-81.

37. Robertsson B, Blennow K, Wallin A. Delirium in dementia. Int J Geriatr Psych .1998; 13:49-56.

38. Inouye SK, Bogardus ST, Charpentier PA., Leo-Summerw DA, Holford TR., Cooney LM. A multicomponent intervention to prevent delirium in hospitalized older patients. N Engl J Med. 1999;340:669-76.

39. Marcantonio ER, Flacker JM, Wright RJ, Resnick NM. Reducing delirium after hip fracture: a randomized trial. J Am Geriatr Soc. 2001;49:516-22.

40. Cole M, Mccusker J, Bellavance F, Primeau F, Balley RF, Bonnycastle MJ, et al. Systematic detection and multidisciplinary care of delirium in older medical inpatients: a randomized trial. Can Med Assoc J. 2002;167:753-9. 